\title{
Pengunaan Bahasa Persuasi di Media Sosial dalam Berdakwah pada Akun Facebook 'Yusuf Mansur (Official)'
}

\section{Eva Harista}

STAIN Syaikh Abdurrahman Siddik Bangka Belitung, Indonesia

harista_eva@gmail.com

\begin{abstract}
Abstrak
Dari masa ke masa dakwah mengalami perkembangan yang signifikan, terutama dakwah di media sosial yang dimanfaatkan oleh para Ustaz/Ustazah di Indonesia. Hal ini dapat terlihat dari jutawan follower yang mengikuti dan merespon setiap caption yang diunggah. Follower tersebut tidak hanya berasal dari Indonesia, tetapi juga tersebar di seluruh penjuru dunia. Salah satu Ustaz yang terkenal di Indonesia yang memiliki jutaan follower dalam media sosial yaitu Ustaz Yusuf Mansur.

Jenis penelitian ini adalah penelitian kualitatif. Adapun data dalam penelitian ini, penulis ambil pada akun Facebook 'Yusuf Mansur (Official)' yaitu kiriman yang diunggah pada Bulan Desember 2017 sebanyak 18 caption atau unggahan. Penulis mengkaji bahasa persuasi yang digunakan dalam unggahan tersebut.

Hasil penelitian menunjukkan bahwa Ustaz Yusuf Mansur menggunakan bahasa persuasi dalam setiap unggahannya. Ia mengajak para komunitasnya untuk melakukan kebaikan-kebaikan seperti yang diperintahkan Allah dan Rasul. Bahasa persuasi yang digunakan tidak selalu menggunakan bahasa Indonesia, tetapi juga bahasa daerah, sehingga terkesan santai dan sederhana, dan mudah dipahami. Bahasa persuasi yang digunakan bertujuan untuk mengajak, membujuk, menghimbau, menyarankan, menasihati, menawarkan, mempromosikan, menyindir, megingatkan, menginformasikan, dan meyakinkan para komunitasnya. Bahasa persuasi dakwah Ustaz Yusuf Mansur dapat mengubah cara berpikir, dapat memberikan manfaat, dapat menyejukkan hati, dapat memberikan pengaruh yang besar bagi kehidupan, dapat mengajak kepada kebaikan, dan memberikan perubahan bagi komunitasnya.
\end{abstract}

Kata kunci; dakwah, media sosial, bahasa persuasi. 


\section{A. Pendahuluan}

edia sosial seperti Facebook, Twitter, Youtobe, Flickr, Blogger, Instagram, dan lain-lain mengalami perkembangan yang sangat pesat saat ini. Media sosial tersebut telah membawa perubahan pola berkomunikasi antar satu orang dengan orang lain. Proses berkomunikasi yang dahulunya hanya dapat dilakukan dengan satu arah secara langsung melalui tatap muka, sekarang mengalami perubahan yang signifikan yaitu dapat melalui internet tanpa harus bertemu secara langsung. Menurut Nurudin, proses komunikasi yang terjadi membawa konsekuensi di tingkat individu, organisasi, dan kelembagaan. ${ }^{1}$ Proses berkomunikasi tersebut salah satunya adalah dalam berdakwah di media sosial.

Dari masa ke masa dakwah mengalami perubahan dan perkembangan yang signifikan, terutama dakwah di media sosial. Para Ustaz/Ustazah kondang Indonesia pun memiliki akun pribadi di jejaring sosial. Mereka memanfaatkan media sosial tersebut untuk berdakwah secara lisan maupun tulisan. Dakwah di media sosial ini terasa sangat efektif. Hal ini dapat terlihat dari jutawan follower yang mengikuti dan merespon setiap caption yang diunggah para Ustaz/Ustazah. Follower tersebut tidak hanya berasal dari Indonesia, tetapi juga tersebar di seluruh penjuru dunia. Maka, bukan hal yang mustahil apabila dakwah di media sosial memiliki peran yang sangat dominan dalam era globalisasi sekarang ini.

Salah satu Ustaz yang terkenal di Indonesia yang memiliki jutaan follower dalam setiap akun resminya yaitu Ustaz Yusuf Mansur. Ustaz Yusuf Mansur mempunyai akun di beberapa media sosial, yaitu akun 'Yusuf Mansur (Official)' di media sosial Facebook, akun 'yusuf_mansur' di media sosial Twitter, akun 'yusufmansurnew' di media sosial Instagram, akun dengan alamat website 'www.yusufmansur.com' di media sosial Blogger, dan akun dengan alamat website 'www.youtobe.com/yusufmansur1912' di media sosial Youtobe.

Penelitian ini akan membahas salah satu akun media sosial yang dimiliki oleh Ustaz Yusuf Mansur. Adapun media sosial yang penulis pilih adalah Facebook dengan akun 'Yusuf Mansyur (Official)'. Dalam akun ini, Ustaz Yusuf Mansur telah memiliki komunitas sebanyak 7.125.650 orang yang menyukai, dan sebanyak 7.088.417 orang

${ }^{1}$ Nurudin, 'Media Sosial Baru dan Munculnya Revolusi Proses Komunikasi', Jurnal Komunikator, vol. 5 (2010), p. 83. 
yang mengikuti. Jumlah komunitas ini diperkirakan akan terus meningkat seiring perkembangan kemajuan teknologi informasi.

Dalam sehari, Ustaz Yusuf Mansur mengunggah kurang lebih tiga hingga lima kali caption atau status atau postingan. Setiap caption tertulis yang diunggah atau diposting oleh Ustaz Yusuf Mansur selalu menggunakan bahasa persuasi. Beliau selalu mengajak para komunitasnya untuk melakukan kebaikan-kebaikan seperti yang diperintahkan Allah dan Rasul. Pada setiap caption atau status atau postingan yang beliau unggah selalu mendapat tanggapan dari komunitasnya. Tanggapan tersebut berupa ribuan "like" yang menandakan "suka, super, wow" dan ratusan komentar, serta ratusan kali caption atau status atau postingan yang diunggah tersebut dibagikan atau diteruskan kembali oleh komunitasnya ke akun mereka masing-masing.

Oleh karena itu, penulis tertarik untuk melihat sejauh mana penggunaan bahasa persuasi Ustaz Yusuf Mansur dalam berdakwah secara tertulis pada akun resminya 'Yusuf Mansur (official)' di media sosial Facebook, sehingga melalui bahasa persuasi dakwah tersebut bisa mempengaruhi kehidupan para anggota komunitasnya.

\section{B. Bahasa Persuasi}

Kata persuasi diturunkan dari verba to persuade, yang artinya membujuk atau menyarankan. Persuasi mula-mula memaparkan gagasan dengan alasan, bukti atau contoh untuk meyakinkan pembaca. Kemudian diikuti dengan ajakan, bujukan, rayuan, imbauan, atau saran kepada pembaca. ${ }^{2}$

Menurut Keraf persuasi adalah suatu seni verbal yang bertujuan untuk meyakinkan seseorang agar melakukan sesuatu yang dikehendaki oleh pembicara (bentuk lisan, misalnya pidato) atau oleh penulis (bentuk tulisan, cetakan, elektronik) pada waktu sekarang atau pada waktu yang akan datang. ${ }^{3}$ Sejalan dengan penjelasan di atas, Suparno dan Yunus memaparkan persuasi berisi paparan berdaya bujuk, berdaya ajuk, ataupun berdaya himbau yang dapat membangkitkan ketergiuran pembaca untuk meyakini dan menuruti himbauan implisit dan kemauan eksplisit yang dilontarkan oleh penulis. ${ }^{4}$

${ }^{2}$ A. Wiyanto, Terampil Menulis Paragraf (Jakarta: PT Gramedia Widiasarana Indonesia, 2004), p. 68.

${ }^{3}$ Gorys Keraf, Komposisi (Jakarta: Ikrar Mandiri Abadi, 2006), p. 115.

${ }^{4}$ Suparno and Yunus, Keterampilan Dasar Menulis (Jakarta: Universitas Terbuka, 2008), p. 5.47. 
Menurut Finoza, persuasi bertujuan membuat pembaca percaya, yakin, dan terbujuk akan hal-hal yang dikomunikasikan yang berupa fakta pendapat atau gagasan ataupun perasaan seseorang. ${ }^{5}$ Sedangkan menurut Kosasih persuasi bertujuan untuk memengaruhi pembaca. ${ }^{6}$

Adapun Ciri-ciri persuasi yaitu sebagai berikut: ${ }^{7}$

1. Harus menimbulkan kepercayaan pendengar/pembacanya.

2. Bertolak atas pendirian bahwa pikiran manusia dapat diubah.

3. Harus menciptakan penyesuaian melalui kepercayaan antara pembaca/penulis dan yang diajak berbicara/pembaca.

4. Harus menghindari konflik agar kepercayaan tidak hilang dan tujuan tercapai.

5. Harus ada fakta dan data secukupnya.

Adapun bentuk persuasi yaitu sebagai berikut: ${ }^{8}$

1. Bentuk pidato, misalnya propaganda, kampanye lisan, dan penjual jamu di tempattempat terbuka.

2. Bentuk tulisan berupa iklan dan selebaran.

3. Bentuk elektronik, misalnya iklan di televisi, bioskop, dan internet.

Dari penjelasan-penjelasan di atas, dapat disimpulkan bahwa bahasa persuasi adalah berupa ajakan dan imbauan kepada orang lain dengan menggunakan kata permintaan maupun perintah atau larangan seperti kata ayo, mari, silakan, jangan, dan lain-lain.

\section{Media Sosial}

Terdapat beberapa pengertian media sosial dari berbagai ahli, sebagai berikut:

Menurut Mandibergh, media sosial adalah media yang mewadahi kerjsama di antara pengguna yang menghasilkan konten (user generated content). Menurut Shirky, media sosial dan perangkat lunak sosial merupakan alat untuk meningkatkan kemampuan pengguna untuk berbagi (to share), bekerja sama (to coperate) di antara

\footnotetext{
${ }^{5}$ Lamudin Finoza, Komposisi Bahasa Indonesia (Jakarta: Diksi Insan Mulia, 2008), p. 247.

${ }^{6}$ E. Kosasih, Kompetensi Ketatabahasaan dan Kesusastraan (Bandung: Yrama Widya, 2003), p. 9.

${ }^{7}$ Dalman, Keterampilan Menulis (Jakarta: PT. Grafindo Persada, 2014), p. 147.

${ }^{8}$ Ibid., p. 151.
} 
pengguna dan melakukan tindakan secara kolektif yang semuanya berada di luar kerangka institusional maupun organisasi. ${ }^{9}$

Hal senada diungkapkan oleh Boyd yang menjelaskan bahwa media sosial sebagai kumpulan perangkat lunak yang memungkinkan individu maupun komunitas untuk berkumpul, berbagi, berkomunikasi, dan dalam kasus tertentu saling berkolaborasi atau bermain. Media sosial memiliki kekuatan pada user generated content (UGC) di mana konten dihasilkan oleh pengguna, bukan oleh editor sebagaimana di institusi media massa. ${ }^{10}$

Pada dasarnya, media sosial merupakan hasil dari perkembangan teknologi baru yang ada di internet, dimana para penggunanya bisa dengan mudah untuk berkomunikasi, berpartisipasi, berbagi, dan membentuk sebuah jaringan di dunia virtual, sehingga para pengguna bisa menyebarluaskan konten mereka sendiri. ${ }^{11}$

Adapun karakteristik media sosial yaitu sebagai berikut: ${ }^{12}$

1. Jaringan

Jaringan adalah sebuah teknologi seperti komputer yang berguna untuk menghubungkan antara komputer dengan perangkat keras lainnya.

2. Informasi

Dalam media sosial informasi menjadi sebuah komoditas dalam masyarakat informasi, karena informasi diproduksi, dipertukarkan, dan dikonsumsi sehingga menjadikan informasi itu komoditas bernilai dalam bentuk baru dari kapitalisme.

3. Arsip

Arsip menjadi bagian penting dalam media sosial, karena arsip ini yang akan menjadikan sebuah informasi tersimpan dan bisa diakses kapan pun dan melalui perangkat apapun.

4. Interaksi

Di media sosial interaksi yang sering terjadi biasanya berbentuk saling memberikan tanda atau mengomentari, misalnya tanda jempol 'Like' di Facebook. Ada

${ }^{9}$ Rulli Nasrullah, Media Sosial: Perspektif Komunikasi, Budaya, dan Sosioteknologi (Bandung: Simbiosa Rekatama Media, 2015), p. 11

${ }^{10}$ Ibid.

${ }^{11}$ Dan Zarella, The Sosial Media Marketing Book (Canada: O’Reilly Media, 2010), p. 2-3.

12 Rulli Nasrullah, Media Sosial, p. 16-34. 
juga sebuah video yang diunggah ke Youtobe mendapatkan tanggapan dan komentar yang banyak.

\section{Simulasi Sosial}

Baudrillard mengungkapkan gagasan simulasi bahwa kesadaran akan yang real di benak khalayak semakin berkurang dan tergantikan dengan realitas semu.

6. Konten oleh pengguna

Konten oleh pengguna (User Generated Content / UGC) adalah sebagai penanda bahwa dalam media sosial, penggunanya tidak hanya memproduksi konten tetapi juga mengonsumsi konten yang juga diproduksi oleh pengguna lainnya.

7. Penyebaran

Penyebaran konten di media sosial bisa dilihat dalam dua jenis. Pertama, penyebaran melalui konten, dan kedua, penyebaran melalui perangkat.

Jenis-jenis media sosial menurut Kaplan dan Haenlein, yaitu sebagai berikut: 13

1. Proyek Kolaborasi yaitu jenis media sosial yang dapat memungkinkan penggunanya untuk membuat konten secara bersama-sama.

2. Blog merupakan jenis media sosial yang di dalamnya pengguna bisa mengunggah tulisan pribadinya.

3. Komunitas Konten adalah jenis media sosial yang membuat penggunanya bisa membagikan konten baik berupa tulisan, gambar, ataupun video.

4. Situs Jejaring Sosial adalah jenis media sosial yang memungkinkan penggunanya untuk berhubungan dengan pengguna lain dengan cara saling berinteraksi seperti mengirimkan pesan, gambar, ataupun video.

5. Virtual Game Word adalah jenis media sosial yang membuat penggunanya untuk saling berinterkasi dengan menggunakan avatar pribadi dan saling berinteraksi seperti dalam dunia nyata.

6. Virtual sosial world merupakan jenis media sosial yang mana penggunanya bisa mensimulasikan kehidupan nyata melalui internet, dan penggunanya merasa hidup dalam dunia virtual, dan merasakan nuansa tiga dimensi.

${ }^{13}$ M. Kaplan and Michael Haenlein, Users of the World Unite! The Challenges and Opportunities of Social Media (Business Horizons, 2010), p. 62-4. 


\section{Dakwah di Media Sosial}

Menurut bahasa, dakwah berasal dari kata berbahasa Arab yakni da'a, yad'u, dakwatan, yang artinya mengajak, menyeru, dan mendorong. ${ }^{14}$ Sedangkan menurut istilah secara umum dakwah adalah ajakan atau seruan kepada yang baik dan yang lebih baik. ${ }^{15}$ Dakwah mengandung arti kewajiban yang menjadi tanggung jawab seorang Muslim dalam amar ma'ruf nahi mungkar. ${ }^{16}$ Pengertian dakwah secara ideal dan makro, baik yang dilakukan oleh individu maupun kelompok (organisasi) harus dilakukan dengan menguasai berbagai aspek, baik metode, materi, media, dan menguasai sasaran dakwah. ${ }^{17}$

Dakwah merupakan sebuah rangkaian kegiatan atau proses dalam mencapai tujuan tertentu. Di era ini, dakwah tidak hanya cukup disampaikan melalui lisan tanpa adanya perangkat pendukung, yang saat ini dikenal dengan sebautan alat-alat komunikasi massa, yaitu media cetak maupun elektronik. ${ }^{18}$

Secara sosiologis, penerapan teknologi komunikasi dan informasi dalam kehidupan telah mengubah ragam interaksi masyarakat. masyarakat dakwah kini bukan saja mereka yang berada di depan mata, melainkan juga mereka yang secara bersamasama ada di ruang abstrak yang disebut dunia maya. Media telah menggiring individu memasuki ruang yang memungkinkan saling berinteraksi, misalnya melalui internet yang dikenal dengan istilah cyberspace. ${ }^{19}$ Penggunaan media internet sebagai media dakwah merupakan kesempatan dan tantangan untuk mengembangkan dan memperluas cakrawala dakwah islamiyah. Dari sisi dakwah, kekuatan internet sangat potensial untuk dimanfaatkan. ${ }^{20}$

Secara khusus, terdapat tiga alasan mengapa dakwah melalui internet menjadi penting, yaitu sebagai berikut:21

${ }^{14}$ Nasron Munawwir, Kamus Al-Munawwir (Yogyakarta: Pustaka Progresif, 1994), p. 106.

15 Wahyu Ilaihi, Komunikasi Dakwah (Bandung: Remaja Rosdakarya, 2010), p. 17.

16 Wahidin Saputra, Pengantar Ilmu Dakwah (Jakarta: PT. Raja Grafindo Persada), p. 2.

17 Eneng Purwanti, 'Manajemen Dakwah dan Aplikasinya bagi Pengembangan Organisasi Dakwah', Jurnal Adzikra, vol. 1, no. 2 (2010), p. 6.

${ }^{18}$ Abdul Munir Mulkhan, Ideologisasi Gerakan Dakwah (Yogyakarta: SIPRESS, 1996), p. 58.

${ }^{19}$ Asep Saeful Muhtadi, Komunikasi Dakwah: Teori, Pendekatan, dan Aplikasi (Bandung: Simbiosa Rekatama Media, 2012), p. 60.

20 Nur Ahmad, 'Tantangan Dakwah di Era Teknologi dan Informasi: Formulasi Karakteristik, Popularitas, dan Materi di Jalan Dakwah', Jurnal Addin, vol. 8 (2014), p. 326-7.

${ }^{21}$ Fathul Wahid, E-Dakwah: Dakwah Melalui Internet (Yogyakarta: Gava Media, 2004), p. 30. 
1. Muslim telah menyebar ke seluruh penjuru dunia. Internet merupakan sarana yang mudah dan murah untuk selalu keep intouch dengan komunitas muslim yang tersebar di segala penjuru dunia.

2. Citra Islam yang buruk akibat pemberitaan satu sisi oleh banyak media Barat perlu diperbaiki. Internet menawarkan kemudahan untuk menyebarkan pemikiranpemikiran jernih dan benar serta pesan-pesan ke-Tuhan-an ke seluruh dunia.

3. Pemanfaatan internet untuk dakwah, dengan sendirinya juga menunjukkan bahwa muslim juga bisa menyesuaikan diri dengan perkembangan peradaban yang ada, selama tidak bertentangan dengan akidah.

Ada beberapa hal penting yang harus diperhatikan ketika berdakwah di dunia maya menurut Syekh Sulthan Al-Umari dalam makalahnya Istikhdam al-Internet fi adDa'wah, yaitu sebagai berikut: 22

1. Hal yang paling mendasar adalah meluruskan niat. Dakwah di internet akan mulus bila didasari dengan niat dan iktikad yang baik, sebaliknya bukan bertujuan untuk mengeruk materi atau larut dengan perdebatan mazhab.

2. Merumuskan visi dan misi berdakwah di dunia maya. Perlu diketahui bahwa esensi berdakwah adalah memberikan manfaat untuk orang lain dan mengajak ke arah kebaikan dan ranah positif.

3. Tunjukkan pada dunia keagungan nilai-nilai luhur Islam.

4. Pilihlah pembimbing atau pengontrol kualitas konten yang berkompeten.

5. Konten selalu disesuaikan dengan kebutuhan masa kini dan kecenderungan masyarakat sekarang.

6. Jika membuat situs dakwah tertentu maka jangan lupa melengkapinya dengan aplikasi-aplikasi unggulan, seperti forum, mengobrol langsung (chatting) dan fasilitas surat elektronik (e-mail).

Dalam menggunakan media sosial sebagai ladang dakwah, terdapat kelebihan dan kekurangan. Kelebihan berdakwah di media sosial yaitu sebagai berikut: ${ }^{23}$

${ }^{22}$ Ahmad Zaini, 'Dakwah Melalui Internet', At-Tabsyir Jurnal Komunikasi Penyiaran Islam, Vol. 1 (2013), p. 94.

${ }^{23}$ Pardianto, 'Meneguhkan Dakwah melalui New Media', Jurnal Komunikasi Islam, vol. 3 (2013), p. 33. 
1. Tidak terhalang oleh ruang dan waktu. Internet bisa diakses kapanpun, dimanapun, oleh siapapun, diberbagai penjuru dunia. Sehingga materi dakwah yang dilakukan di media sosial bisa diakses oleh semua orang tanpa dibatasi ruang dan waktu.

2. Dakwah menjadi lebih variatif. Para pelaku dakwah di media sosial bisa membuat materi dakwah dalam bentuk gambar, audio, video dan lain-lain, sehingga para objek dakwah di media sosial bisa memilih sesuai dengan yang mereka sukai.

3. Jumlah pengguna internet semakin meningkat. Dengan pertumbuhan pengguna internet yang selalu mengalami peningkatan, maka hal ini merupakan kabar baik bagi pelaku dakwah di media sosial.

4. Hemat biaya dan energi. Dengan melakukan dakwah di media sosial, para juru dakwah tidak perlu mengeluarkan biaya yang mahal dan tidak perlu mengeluarkan banyak energi untuk melakukan dakwahnya. Hal ini dikarenakan cukup dengan bermodalkan perangkat seperti komputer atau smartphone ditambah dengan koneksi internet, bisa dalam keadaan santai atau di rumah, kegiatan dakwah di media sosial sudah bisa dilakukan.

Adapun kekurangan berdakwah di media sosial, yaitu sebagai berikut:24

1. Untuk beberapa kalangan masyarakat, Internet adalah media komunikasi yang mahal.

2. Secara psikologi berdakwah melalui internet menghilangkan tali silaturrahmi secara fisik dan psikologis.

3. Sulit mengetahui terjadi perubahan di bidang perilaku di kalangan Mad'u, karena sifat Mad'u yang tersebar dan terpencar.

\section{E. Metode Penelitian}

Jenis penelitian ini adalah penelitian kualitatif. Menurut Ghony dan Fauzon Almanshur, penelitian kualitatif adalah penelitian yang menghasilkan penemuanpenemuan yang tidak dicapai dengan menggunakan prosedur statistik, tetapi dicapai dengan menunjukkan kehidupan masyarakat, sejarah, tingkah laku, fungsionalisasi organisasi, dan hubungan kekerabatan. ${ }^{25}$ Dalam pelaksanaannya, penelitian ini tidak terkait tempat karena objek penelitian ini berupa wacana bahasa tulis di media sosial

${ }^{24}$ Ibid., p. 8.

${ }^{25}$ M Diunaidi Ghony and Fauzan Almanshur, Metodologi Penelitian Kualitatif (Yogyakarta: ArRuzz Media, 2012), p. 25. 
dalam sebuah akun facebook. Objek dan data penelitian ini adalah bahasa tulis berupa kalimat persuasi dalam akun facebook Yusuf Mansur (Official)'.

Dalam penelitian ini, penulis menggunakan metode simak dengan teknik catat. Penulis mencatat beberapa bentuk yang dianggap relevan atau dapat dimasukkan ke dalam penelitian dari penggunaan bahasa tulis tersebut. Sedangkan untuk metode analisis data, penulis menggunakan metode padan intralingual. Metode padan intralingual digunakan untuk menganalisis unsur yang bersifat intralingual, seperti menghubungkan masalah bahasa dengan yang berada di dalam bahasa. ${ }^{26}$

Adapun data dalam penelitian ini, penulis ambil pada akun Facebook Yusuf Mansur (Official)' yaitu kiriman Ustaz Yusuf Mansur yang diunggah pada Bulan Desember 2017, yaitu sebanyak 18 caption atau unggahan.

\section{F. Penggunaan Bahasa Persuasi di Media Sosial dalam Berdakwah pada Akun Facebook Yusuf Mansur (Official)'}

Media sosial yang dipilih dalam penelitian ini adalah Facebook dengan pemilik akun 'Yusuf Mansyur (Official)'. Pemilik akun ini merupakan salah satu seorang Ustaz kondang Indonesia yang telah melanglangbuana dalam dunia dakwah.

Akun Facebook 'Yusuf Mansur (Official)' merupakan akun resmi yang berlabelkan dakwah dari Ustaz Yusuf Mansur dengan jumlah foollower lebih dari Tujuh Juta orang. Dalam setiap postingan yang dikirim ke akun ini, terdapat ribuan "like" dan komentar dari para komunitasnya. Dalam setiap postingannya, Ustaz Yusuf Mansur sering menggunakan bahasa persuasi dalam berdakwah di media sosial. Hal ini karena dakwah memang mengajak orang ke jalan kebaikan dan mencegah kepada kemungkaran.

Bahasa yang digunakan Ustaz Yusuf Mansur dalam dakwahnya terkesan santai, sederhana, dan menggunakan perpaduan antara bahasa Indonesia dan bahasa Daerahnya, sehingga mudah dipahami semua kalangan. Berikut adalah hasil temuan dari penelitian yang dilakukan:

1)@Yusuf Mansur (Official) “OneQuran hadir di mabit Telkomsel hari ini-besok. Siapa yang mau hadir? kita belajar Qur'an bareng-bareng silahkan kalau ada pertanyaan

26 Mahsun, Metode Penelitian Bahasa: Tahap Strategi, Metode, dan Tekniknya, (Jakarta: PT. Rajagrafindo Persada, 2005), p. 114. 
tentang cara belajar dan lain-lain. Ada yang mau kantornya didatangi juga? Komen ya." (15 Desember 2017)

Penggalan data di atas menggunakan bahasa persuasi sebanyak tiga kali. Bahasa persuasi pertama, Ustaz Yusuf Mansur mengajak para follower untuk hadir di acara mabit Telkomsel. Bahasa persuasi kedua, beliau mengajak follower untuk belajar Al-Quran bersama-sama. Bahasa persuasi ketiga, Ustaz yusuf Mansyur menawarkan segaligus mengajak follower untuk memberikan komentar bagi yang ingin kantor mereka dikunjungi oleh beliau.

2)@Yusuf Mansur (Official) "Jangan nyari tembok sama tiang, Dengan niat nyender buat tiduran ya... Sayang. Udah mah jarang jamaah, sekalinya Jumatan, tidur..." (15 Desember 2017)

Penggalan data kedua tersebut menggunakan bahasa persuasi yaitu mengajak para follower agar tidak tidur pada saat shalat Jumat. Bahasa yang digunakan berupa sindiran untuk mengajak ke arah kebaikan.

3) @Yusuf Mansur (Official) “...Mari pergunakan waktu kita untuk hal yang baik, bekerja, belajar. Salah satunya belajar Qur'an..." (14 Desember 2017)

Penggalan data ketiga tersebut, Ustaz Yusuf Mansur mengajak para follower agar senantiasa menggunakan waktu untuk sesuatu yang baik seperti bekerja, belajar, membaca Al-Quran.

4)@Yusuf Mansur (Official) “Pada saat dulu saya bermasalah, sungguhyang saya cari yaitu Al-Qur'an, untuk menenangkan hati saya, untuk menentramkan hati saya. Dan saya cari satu demi satu ayat-ayat yang bisa bikin saya termotivasi lagi. Dan ayat ini yang bisa buat saya tenang dan tentram... selengkapnya di http://yusufmansur.com/yang-bisa-buat-kita-tenang/" (14 Desember 2017)

Pada penggalan berikutnya, Ustaz Yusuf Mansur bercerita tentang keadaan dirinya yang dulu pernah mempunyai masalah. Masalah tersebut beliau selesaikan dengan mengkaji Al-Quran. Secara implisit, pesan dari penggalan kalimat di atas adalah beliau mengajak para follower untuk mengikuti jejak beliau sebelumnya ketika punya masalah. Pada akhir kalimat nya, Ustaz Yusuf Mansur menginformasikan sekaligus mengajak follower untuk membuka link beliau di alamat website yang berjudul "yang bisa membuat kita tenang." 
5) @Yusuf Mansur (Official) “Ayo lanjutin ya. belajar Qur'an di OneQuran udah bisa mulai dari jam segini, jam 5 pagi-9 malam, senin sampai sabtu... Yuk ngaji online!" (14 Desember 2017)

Penggalan data kelima di atas menunjukkan bahwa Ustaz Yusuf Mansur mengajak follower untuk belajar Al-Quran secara online di OneQuran, mulai dari Pukul 05.00 WIB sampai dengan Pukul 21.00 WIB, dari Hari Senin sampai Sabtu.

6) @Yusuf Mansur (Official) "Jangan kurang-kurang shalawatnya. Sehari semalam, mbok ya minim-minim 100. Syukur-syukur 100 pagi 100 sore. Syukur-syukur lagi 1000. Dan jangan sehari doangan. Jadi pakean rutin aja. Banyak berkahnya hidup itu jika mencintai shalawat..." (13 Desember 2017)

Pada penggalan data di atas, Ustaz Yusuf Mansur menggunkan bahasa persuasi yaitu mengingatkan dan mengajak follower untuk selalu membaca, mencintai, dan mengamalkan salawat secara rutin, agar hidup menjadi berkah.

7) @Yusuf Mansur (Official) “Orang yang kuat, suku yang kuat, kaum yang kuat, kampung yang kuat, daerah yang kuat, kota yang kuat, negara yang kuat, tidak sedikit yang banyak masalahnya. Yang banyak tantangannya. Yang banyak problemanya. Yang banyak kesulitannya. Lalu mereka bisa keluar sebagai pemenang. Karena ada Allah justru yang semakin menguatkan..." (13 Desember 2017)

Penggalan data di atas, Ustaz Yusuf Mansur mencoba meyakinkan para follower untuk percaya dan yakin kepada Allah, bahwa segala sesuatu permasalahan dan kesulitan/cobaan berat yang dialami akan dapat teratasi, karena ada Allah yang selalu menguatkan.

8)@Yusuf Mansur (Official) “Allah selalu punya skenario terindah untuk hamba-Nya. Kita hanya perlu bersabar dan ikhlas dalam menanti. Bersyukur atas semua kebaikan dan ujian yang Allah berikan pada kita. Kita hanya perlu menjadi hambaNya yang taat. Banyakin baca Qur'an, perbaiki bacaannya, pahami artinya. Hayuk bareng-bareng belajar Qur'an dan perbaiki bacaannya di OneQuran..." (13 Desember 2017)

Penggalan data pada kalimat pertama di atas, menunjukkan bahwa Ustaz Yusuf Mansyur menggunakan bahasa persuasi yaitu mengajak follower untuk bersabar, ikhlas, dan bersyukur atas semua kebaikan dan ujian yang diberikan Allah. Pada kalimat kedua, 
Ustaz Yusuf Mansur kembali mengingatkan kepada follower agar menjadi hamba yang taat. Selanjutnya Ustaz Yusuf Mansur mengajak follower untuk memperbanyak membaca Al-Quran, memperbaiki bacaan Al-Quran, dan memahami makna Al-Quran. Kalimat terakhir, Ustaz Yusuf Mansur mengajak follower untuk belajar Al-Quran secara online di OneQuran.

9) @Yusuf Mansur (Official) "Jangan ampe konyol, tidur dalam keadaan ga wudhu. Dan ga baca Al-Mulk. Kematian bisa datang saat tidur. Beresiko tidur tanpa jaminan Allah. Saya nulis buku judulnya "JAMINAN". Isinya membahas tentang Al Mulk. Jaminan Hidup. Bagus loh isinya. Cari aja di bukuyusufmansur.com. Ok. Met Wudhu. Met Shalat sunnah 2 rokaat. Sunnah Taubat. Or Hajat..." (12 Desember 2017)

Penggalan data di atas, Ustaz Yusuf Mansur mengingatkan follower agar berwudhu dan membaca surah Al-Mulk ketika akan tidur. Selanjutnya, Ustaz Yusuf Mansur mempromosikan isi buku karyanya yang berjudul "JAMINAN", sekaligus beliau mengajak follower untuk membaca dan mempelajari buku beliau lebih lanjut di website: bukuyusufmansur.com.

10)@YusufMansur (Official) “Ya. sebab ampunan Allah itu lebih penting. Mahal sekali. Lebih mahal dari dunia dan seisinya. Nih liat ya. kalo dah masuk neraka, maka jika dia punya emas seberat dan sebanyak bumi. Lalu punya lagi seberat dan sebanyak itu. Gak bakal bisa nebus..." (12 Desember 2017)

Penggalan data di atas menjelaskan bahwa, Ustaz Yusuf Mansur mengingatkan follower tentang ampunan Allah yang sangat mahal. Ampunan tersebut tidak bisa ditebus emas seberat dan sebanyak bumi, jika sudah masuk neraka. Secara implisit, bahasa persuasi dari kalimat di atas bahwa Ustaz yusuf Mansur mengajak dan menghimbau follower untuk senantiasa memohon ampunan kepada Allah sebelum terlambat.

11)@Yusuf Mansur (Official) "Jangan lupa berdzikir setiap hari, semoga kita menjadi hamba yang selalu bertaqwa... Jangan lupa ya hari ini belajar Qur'an, salah satu bentuk dzikir juga..." (11 Desember 2017)

Penggalan kalimat pertama di atas, Ustaz Yusuf Mansur menggunakan bahasa persuasi yaitu beliau mengingatkan kepada follower untuk tidak lupa berzikir setiap hari. Pada kalimat kedua, Ustaz Yusuf Mansur kembali mengingatkan sekaligus mengajak 
follower untuk tidak lupa belajar Al-Quran, dengan penegasan bahwa belajar Al-Quran merupakan salah satu bentuk zikir juga.

12) @Yusuf Mansur (Official) “...Mbok tiap hari dibaca Qur'an itu dan artinya. Pasang targetlah untuk ngekhatamin arabnya dan artinya. Sebulan... setahun... dua tahun... jangan sampe ga ada target..." (10 Desember 2017)

Penggalan data di atas menggunakan bahasa persuasi, Ustaz Yusuf Mansur menghimbau follower untuk setiap hari membaca Al-Quran dan artinya. Beliau juga mengajak follower untuk membuat target mengkhatamkan Al-Quran baik itu bacaan arabnya maupun terjemahannya.

13) @Yusuf Mansur (Official) "Rasulullah ngasih kita resep sederhana supaya kita terhibur dari kelelahan dunia. Kata Rasul, "Perbanyaklah mengingat kematian, maka kamu akan banyak terhibur dari kelelahan dunia. Hendaklah kamu banyakbanyak menerima keadaan (pandai bersyukur) karena ia akan menambah kenikmatan dari Allah. Perbanyaklah berdoa, sesungguhnya kamu tidak akan tahu kapan doamu akan terkabul..." (8 Desember 2017)

Penggalan data di atas menggunakan bahasa persuasi melalui kutipan Hadist Nabi, Ustaz Yusuf Mansur mengingatkan, menghimbau, dan mengajak follower untuk memperbanyak mengingat kematian, pandai bersyukur, dan memperbanyak berdoa.

14) @Yusuf Mansur (Official) “Minta rizki lebih aja daaaahh... sama Allah. Antisipasi apa2 pada naek." (7 Desember 2017)

Dalam penggalan kalimat di atas, Ustaz Yusuf Mansur menggunakan bahasa persuasi berupa ajakan untuk meminta rezeki hanya kepada Allah. Kalimat persuasi tersebut menghimbau follower untuk berdoa dan yakin kepada rezeki dari Allah, walaupun segala kebutuhan hidup terasa mahal.

15) @Yusuf Mansur (Official) “Pagi-pagi, amalan yang bakal ngangkat derajat, ngubah hidup, ngapun dosa, plus datengin halusnya akhlak: tasbih atau subhaanallaahi wabihamdih, 100 kali. Jangan ditinggal juga loh, 100 shalawat. Baca sekarang dah. Plus 100 istighfar. Amalan-amalan sunnah model begini, bikin dekat sama Allah dan Rasul-Nya." (7 Desember 2017)

Penggalan data di atas menggunakan bahasa persuasi. Ustaz Yusuf Mansur mengajak para follower untuk membaca tasbih, salawat, dan istighfar di setiap pagi hari. Beliau menegaskan pernyataannya untuk meyakinkan follower bahwa amalan-amalan 
sunnah seperti membaca tasbih, salawat, dan istighfar daat membuat kita dekat kepada Allah dan Rasul.

16)@Yusuf Mansur (Official) "Yang terbaik itu memang hanya dari Allah, jadi inget lagi buat selalu ikhlas. Kalau kita ngerasa ga suka sama apa yang terjadi saat ini, ya sabar aja, ikhlas aja, siapa tau berkahnya di situ." (5 Desember 2017)

Penggalan kalimat di atas menggunakan bahasa persuasi. Ustaz Yusuf Mansur kembali mengajak dan menghimbau para follower untuk selalu bersabar dan ikhlas atas segala sesuatu yang diberikan Allah, walaupun sesuatu tersebut tidak disukai. Ustaz Yusuf mansur menguatkan pernyataan beliau di akhir kalimat yaitu ada keberkahan disetiap kasabaran dan keikhlsan.

17) @Yusuf Mansur (Official) "Pernah ga permasalahan tidak mau pergi berlari? Atau pertanyaan yang mulanya dijawab membingungkan, yaitu mengapa badan kita sakit. Jawaban Cang Haji, lihat sikap dan kelakuan kita. Itu, katanya, menandakan badan kita kagak senang dihuni hati yang kagak beres." (5 Desember 2017)

Pada penggalan data di atas, Ustaz Yusuf Mansur menggunakan bahasa persuasi, yaitu mengajak follower untuk mengintrospeksi diri sendiri tentang sikap dan kelakuan, dengan mengutip pernyataan Cang Haji. Sikap dan kelakuan kita menandakan bahwa tubuh tidak senang jika dihuni hati yang tidak baik.

18) @Yusuf Mansur (Official) "Hayuk doa ini setiap sore, banyakin dzikir. Dzikir yang paling baik adalah membaca Qur'an. Baca Qur'an ga sekedar lancar, tapi juga benar makhrojnya dan sesuai tajwid. Belum sempurna bacaannya? Yuk belajar di OneQur'an." (4 Desember 2017)

Penggalan data di atas menggunakan bahasa persuasi. Ustaz Yusuf Mansur mengajak follower untuk membaca doa di setiap sore hari, memperbanyak berzikir. Beliau menegaskan kembali bahwa zikir yang paling baik adalah membaca Al-Quran. Kalimat selanjutnya, Ustaz Yusuf Mansyur mengajak dan menghimbau kepada follower untuk membaca Al-Quran yang benar makhrojnya dan sesuai tajwid. Pada kalimat terakhir, Ustaz Yusuf Mansur menawarkan sekaligus mengajak follower yang belum sempurnya bacaan Qurannya, untuk belajar secara online di OneQuran.

Dalam penggalan-penggalan data di atas, Ustaz Yusuf Mansur menggunakan bahasa persuasi dalam setiap unggahannya. Bahasa persuasi yang digunakan tidak selalu menggunakan bahasa Indonesia, tetapi juga terdapat bahasa persuasi yang menggunakan 
bahasa daerah. Adapun penggunaan bahasa persuasi dalam data di atas yaitu: Mari, Yuk, Hayuk, Ayo, Silahkan, Mbok, Mbok ya, Jangan, Jangan lupa, Jangan sampe, dan menggunakan partikel-lah seperti Perbanyaklah, Banyakinlah, Hendaklah. Bahasa persuasi yang ditandai dengan kata-kata tersebut bertujuan untuk mengajak, membujuk, menghimbau, menyarankan, menasihati, menawarkan, mempromosikan, menyindir, megingatkan, menginformasikan, dan meyakinkan para komunitasnya.

Bahasa persuasi dakwah Ustaz Yusuf Mansur dapat mengubah cara berpikir, dapat memberikan manfaat, dapat menyejukkan hati, dapat memberikan pengaruh yang besar bagi kehidupan, dapat mengajak kepada kebaikan, dan yang penting adalah memberikan perubahan bagi komunitasnya dalam menggapai kebahagiaan di dunia dan akhirat.

\section{G. Penutup}

Ustaz Yusuf Mansur memiliki gaya bahasa perusasi tersendiri dalam berdakwah di media sosial. Bahasa persuasi yang digunakan oleh Ustaz Yusuf Mansur terkesan sederhana, santai, dan sopan. Keunikan bahasa persuasi dalam dakwah Ustaz Yusuf Mansur secara tertulis adalah selalu menyelipkan bahasa daerah, sehingga membuat semua kalangan dapat dengan mudah memahaminya dan mengikuti ajakan, imbauan, dan nasihat yang diberikan.

Adapun bahasa persuasi yang sering muncul dalam bahasa tulis Ustaz Yusuf Mansur adalah “Mari, Yuk, Hayuk, Ayo, Silahkan, Mbok, Mbok ya, Jangan, Jangan lupa, Jangan sampe, dan menggunakan partikel-lah seperti Perbanyaklah, Banyakinlah, Hendaklah." Bahasa persuasi yang ditandai dengan kata-kata tersebut bertujuan untuk mengajak, membujuk, menghimbau, menyarankan, menasihati, menawarkan, mempromosikan, menyindir, megingatkan, menginformasikan, dan meyakinkan para komunitasnya.

Begitu dahsyatnya bahasa persuasi oleh seorang Ustaz Yusuf Mansur bagi para komunitasnya, yang dapat mengubah cara berpikir, dapat memberikan manfaat, dapat menyejukkan hati, dapat memberikan pengaruh yang besar bagi kehidupan, dapat mengajak kepada kebaikan, dan yang penting adalah memberikan perubahan bagi komunitasnya dalam menggapai kebahagiaan di dunia dan akhirat. 


\section{DAFTAR PUSTAKA}

Ahmad, Nur. "Tantangan Dakwah di Era Teknologi dan Informasi: Formulasi Karakteristik, Popularitas, dan Materi di Jalan Dakwah" dalam Jurnal Addin, Vol. 8, 2014.

Dalman. Keterampilan Menulis. Jakarta: PT. Grafindo Persada, 2014.

Finoza, Lamudin. Komposisi Bahasa Indonesia. Jakarta: Diksi Insan Mulia, 2008.

Ghony, M. Djunaidi dan Fauzan Almanshur. Metodologi Penelitian Kualitatif. Yogyakarta: Ar-Ruzz Media, 2012.

Ilaihi, Wahyu. Komunikasi Dakwah. Bandung: Remaja Rosdakarya, 2010.

Kaplan, M dan Michael Haenlein. User of the World Unite! The Challenges and Opportunities of Social Media. Business Horizons, 2010.

Keraf, Gorys. Komposisi. Jakarta: Ikrar Mandiri Abadi, 2006.

Kosasih, E. Kompetensi Ketatabahasaaan dan Kesusastraan. Bandung: Yrama Widya, 2003.

Mahsun. Metode Penelitian Bahasa: Tahap Strategi, Metode, dan Tekniknya. Jakarta: PT. Rajagrafindo Persada, 2005.

Munir, Mulkhan Abdul. Ideologisasi Gerakan Dakwah. Yogyakarta: SIPRESS, 1996.

Muhtadi, Asep Saeful. Komunikasi Dakwah: Teori, Pendekatan, dan Aplikasi. Bandung: Simbiosa Rekatama Media, 2012.

Munawwir, Nasron. Kamus Al-Munawwir. Yogyakarta: Pustaka Progresif, 1994.

Nasrullah, Rulli. Media sosial: Perspektif Komunikasi, Budaya, dan Sosioteknologi. Bandung: Simbiosa Rekatama Media, 2015.

Nuruddin. "Media Sosial Baru dan Munculnya Revolusi Proses Komunikasi” dalam Jurnal Komunikator Vol. 5, 2010.

Pardianto. "Meneguhkan Dakwah Melalui New Media" dalam Jurnal Komunikasi Islam, Vol. 03, Juni 2013.

Purwanti, Eneng. "Manajemen Dakwah dan Aplikasinya bagi Pengembangan Organisasi Dakwah" dalam Jurnal Adzikra Vol. 01. No. 02, 2010.

Saputra, Wahidin. Pengantar Ilmu Dakwah. Jakarta: PT. Raja Grafindo Persada.

Suparno dan Yunus. Keterampilan Dasar Menulis. Jakarta: Universitas Terbuka, 2008.

Wahid, Fathul. E-Dakwah: Dakwah Melalui Internet. Yogyakarta: Gava Media, 2004.

Wiyanto, A. Terampil Menulis Paragraf. Jakarta: PT Gramedia Widiasarana, 2004.

Zaini, Ahmad. "Dakwah Melalui Internet" dalam At-Tabsyir Jurnal Komunikasi Penyiaran Islam, Vol. I, 2013.

Zarella, Dan. The Social Media Marketing Book. Canada: O’Reilly Media, 2010. 